\title{
The Efficacy of Therapeutic Selective Nerve Block in Treating Lumbar Radiculopathy and Avoiding Surgery
}

This article was published in the following Dove Press journal:

Journal of Pain Research

\author{
Tareq Kanaan (iD)' \\ Rami Abusaleh (D) ${ }^{2}$ \\ Jumanah Abuasbeh (D) ${ }^{2}$ \\ Maryam Al Jammal (iD ${ }^{2}$ \\ Sara Al-Haded (iD ${ }^{2}$ \\ Sara Al-Rafaiah (iD ${ }^{2}$ \\ Ali Kanaan iD ${ }^{2}$ \\ Fatima Alnaimat (iD ${ }^{3}$ \\ Lubna Khreesha ${ }^{4}$ \\ Fadi Al Hadidi ${ }^{5}$ \\ Qussay Al-Sabbagh' \\ 'Division of Neurosurgery \& Spine Unit, \\ Special Surgery Department, University \\ of Jordan, Amman, Jordan; ${ }^{2}$ School of \\ Medicine, University of Jordan, Amman, \\ Jordan; ${ }^{3}$ Internal Medicine Department, \\ University of Jordan, Amman, Jordan; \\ ${ }^{4}$ Special Surgery Department, University \\ of Jordan, Amman, Jordan; ${ }^{5}$ Division of \\ Orthopedic Surgery \& Spine Unit, Special \\ Surgery Department, University of \\ Jordan, Amman, Jordan
}

Background: Selective nerve root block (SNRB) is a procedure that can be used as a diagnostic or a therapeutic method. SNRB can be used in multiple sites, including cervical and lumbar . Our study aims to investigate the clinical effectiveness of the use of fluoroscopically guided therapeutic selective nerve root block as a non-surgical symptom management of lumbar radiculopathy.

Patients and Methods: This is a prospective study of therapeutic nerve root block in 76 patients with low back pain and/or sciatica at Jordan University Hospital. Data was collected by independent clinical interviewers, and visual analogue score (VAS) was used to measure pain severity.

Results: A total of 76 patients, 25 (32.8\%) males and 51 (67.2\%) females, underwent SNRB. 69 (90.7\%) patients improved immediately after the procedure. Out of the total, $22(28.9 \%)$ patients showed a long-term relief of symptoms and did not experience any recurrence during the three months of follow-up, while 47 (61.8\%) experienced a recurrence of pain. In patients experiencing recurrence of symptoms, 35 needed surgery.

Conclusion: Therapeutic SNRB is an important procedure in the pain management of patients with lumbar radiculopathy caused by lumbar disc prolapse and foraminal stenosis. Our study showed that avoidance of surgery was achieved in up to $54 \%$ of patients; pain relief for at least 6 months was achieved in up to $29 \%$ of patients after a single SNRB. This makes it a very good second line of management after conservative treatment and a possible method to delay, and sometimes cease, the need for surgery.

Keywords: sciatica, sacroiliac joint, SIJ, lumbar disc herniation, facet joint, peri-radicular therapy, PRT, lumbar disc prolapse, LDP

\section{Introduction}

Lumbar radiculopathy is defined as pain in the lower back, radiating to the lower limb along the course of a certain lumbar nerve caused by a pathological process such as inflammation or mechanical compression of that nerve root. ${ }^{1,2}$ It can affect the quality of life and limit the activities of affected patients. It is mostly caused by lumbar disc prolapse (LDP) compressing the nerve root or nerve root foraminal stenosis. Sciatica is a pain in the distribution of the sciatic nerve. Radicular pain can be associated with numbness, paresthesia, tingling, muscle weakness, and loss of specific reflexes, but even without the presence of these symptoms, we cannot exclude the diagnosis. ${ }^{1,3}$

The compression of the nerve root is mostly caused by herniated discs in approximately $90 \%$ of cases. Additionally, foraminal stenosis and, less often, tumors, cysts, inflammation, and/or nerve root injury are other possible causes. ${ }^{1,4}$
Correspondence: Tareq Kanaan Division of Neurosurgery \& Spine Unit, Special Surgery Department, University of Jordan, Queen Rania St, Amman II 942, Jordan

Tel +962 79973I700

Email tkanaan@web.de
Journal of Pain Research 2020:13 297|-2978

DovePress in $\mathbf{D}$ 
Most sciatica cases can be treated conservatively with rest, muscle relaxants, nonsteroidal anti-inflammatory drugs (NSAIDs), and physiotherapy. ${ }^{5}$ Failure of conservative management is usually considered in the case of continuity of the pain for at least six weeks. ${ }^{4,6}$ On the other hand, the exact timing needed for the patient to stay on the conservative care before switching to another treatment method has not been appropriately evaluated. Meanwhile, an immediate surgical intervention is required in acute settings, especially in those with acute drop foot or bladder incontinence. ${ }^{7}$ In the absence of these red flags, there is much disagreement about surgery's effectiveness in chronic sciatica. ${ }^{8}$ Moreover, many patients might be reluctant to undergo surgery or may not be fit for general anesthesia, making it crucial to search for alternative management like Selective Nerve Root Block. ${ }^{9}$

Selective nerve root block (SNRB) is a procedure that can be used as a diagnostic and therapeutic method. SNRB can be used in multiple sites, including cervical and lumbar. ${ }^{2,9}$ Steroids are usually injected near the spinal nerve as it exits from the intervertebral foramen. The use of steroids is due to their ability to reduce inflammation and induce numbness to the pain transmission through the nerve. ${ }^{9,10}$ The procedure can be done under fluoroscopy or CT guidance. ${ }^{6,11}$ The use of SNRB in patients with severe pain can reduce their pain and thus reduce their need for surgery. ${ }^{6}$ The objective of our study is to investigate the effectiveness of the use of fluoroscopy-guided therapeutic SNRB as a non-surgical option for patients with sciatica due to lumbar disc herniation and/or foraminal stenosis.

\section{Patients and Methods Methodology}

This is a prospective study of therapeutic nerve root block in patients with sciatica at Jordan University Hospital. Approval was obtained from the Institutional Review Board (IRB) number (67/2018/1535) at our institution. This study was conducted according to guidelines set in the Declaration of Helsinki. All participants provided written informed consent before study enrollment. The study's data was collected from the Neurosurgery Department at Jordan University Hospital, between January 2018 and December 2019.

\section{Study Population}

All patients initially included in the study described severe sciatica for three to six months with a VAS of $8 / 10$ and above $(n=779)$. Patients with associated cervical radiculopathy, cauda equina syndrome, clinically documented motor weakness, traumatic lumbar radiculopathies, or previous spine surgeries were excluded. All patients with documented malignancies or inflammatory diseases were excluded as well $(\mathrm{n}=358)$.

All remaining patients had a trial of conservative treatment for at least 4-6 weeks $(n=421)$. The conservative therapy consisted of bed rest for three days, NSAIDs, muscle relaxants, occasional use of antiepileptics like Gabapentin, and supervised physiotherapy. They were followed up weekly to look for progression or deterioration of their signs and symptoms. During the follow-up period, patients with intractable pain who could not tolerate conservative management or those who developed neurological deficits were excluded and offered surgery $(n=345)$. Only those who failed to improve after 4-6 weeks of conservative treatment and their VAS remained 8/10, and above were included in our study $(n=76)$ [Figure 1].

\section{SNRB Procedure}

Those patients were then offered therapeutic SNRB, and the procedure was explained clearly. SNRB was done by injecting a combination of bupivacaine and methylprednisolone around the corresponding nerve root causing sciatica under local anesthesia. The procedure is performed by putting the patient in a supine position, preferably on a carbon table in the operating theater. After cleaning and draping, a 22 gauge spinal needle is placed lateral to the midline at the level of the nerve root affected. One $\mathrm{mL}$ of iohexol dye $300 \mathrm{mg} / \mathrm{mL}$, a water-soluble contrast, was used to identify if the needle is properly located using both AP and lateral views to avoid injecting into a blood vessel. Fluoroscopy guidance is almost always used to locate the required nerve root (Figures 2 and 3). Once this is confirmed, a mixture of anesthetic ( $2 \mathrm{~mL}$ of bupivacaine $\mathrm{Hcl} 0.5 \%$, one vial contains $20 \mathrm{~mL}$ $100 \mathrm{mg}$ ) and an anti-inflammatory medication (methylprednisolone $2 \mathrm{~mL}-40 \mathrm{mg}$ ) is injected.

\section{Data Collection}

A trained interviewer using a standardized questionnaire interviewed the subjects. Data were collected on age, gender, the severity of pain at 4 points in time (immediately after the procedure, one month, two months, and three months after), level of pathology, presentation of back pain and/or sciatica, recurrence of pain, improvement of symptoms, and if the patient needed surgery. 


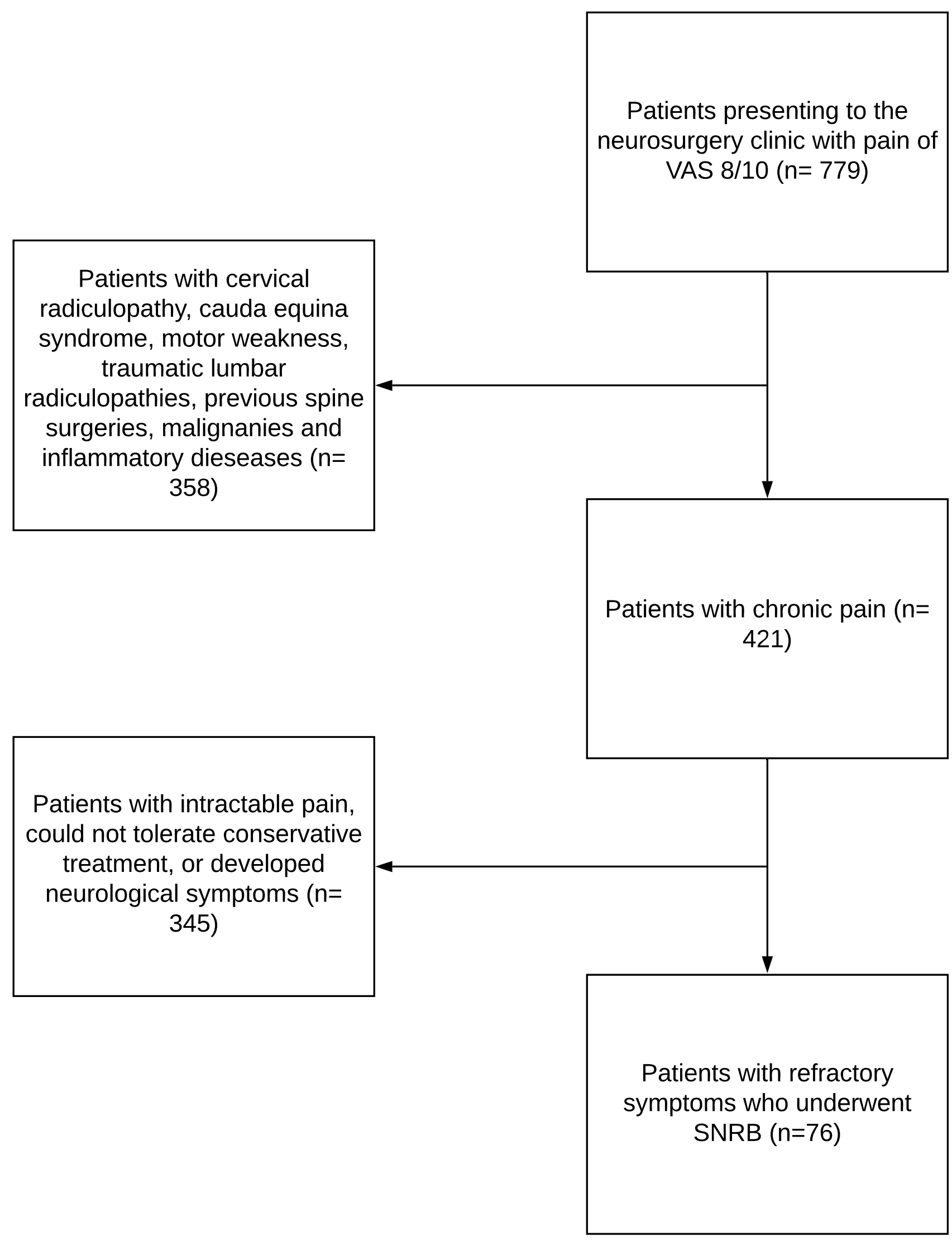




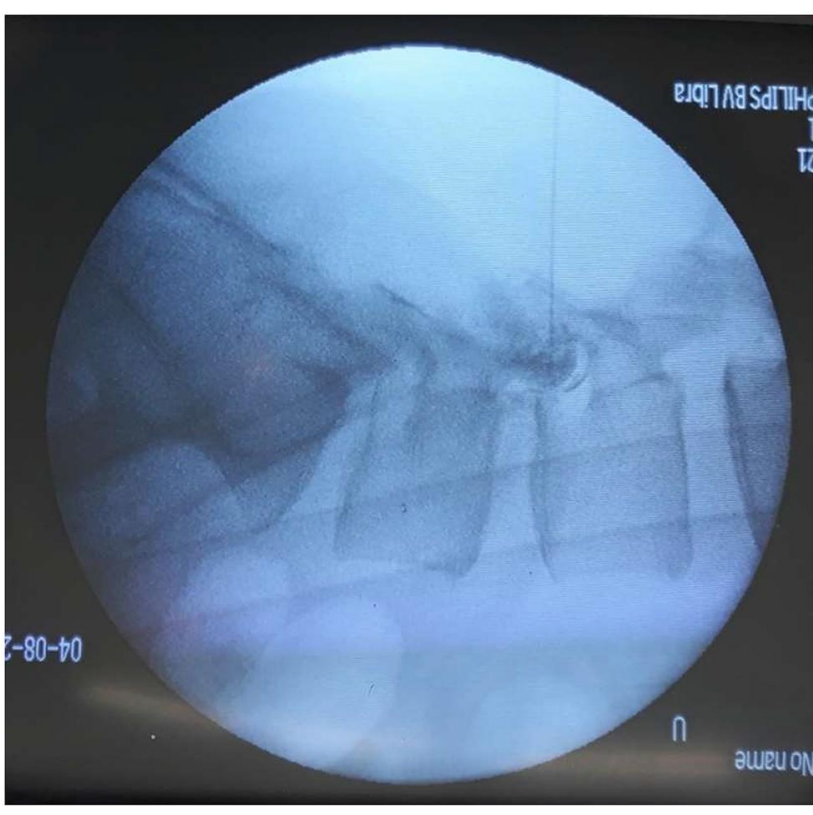

Figure 2 Fluoroscopic image of the lumbar spine in lateral view showing the tip of needle positioned at the upper part of the L4 foramen and dye flowing around the nerve root within the foramen.

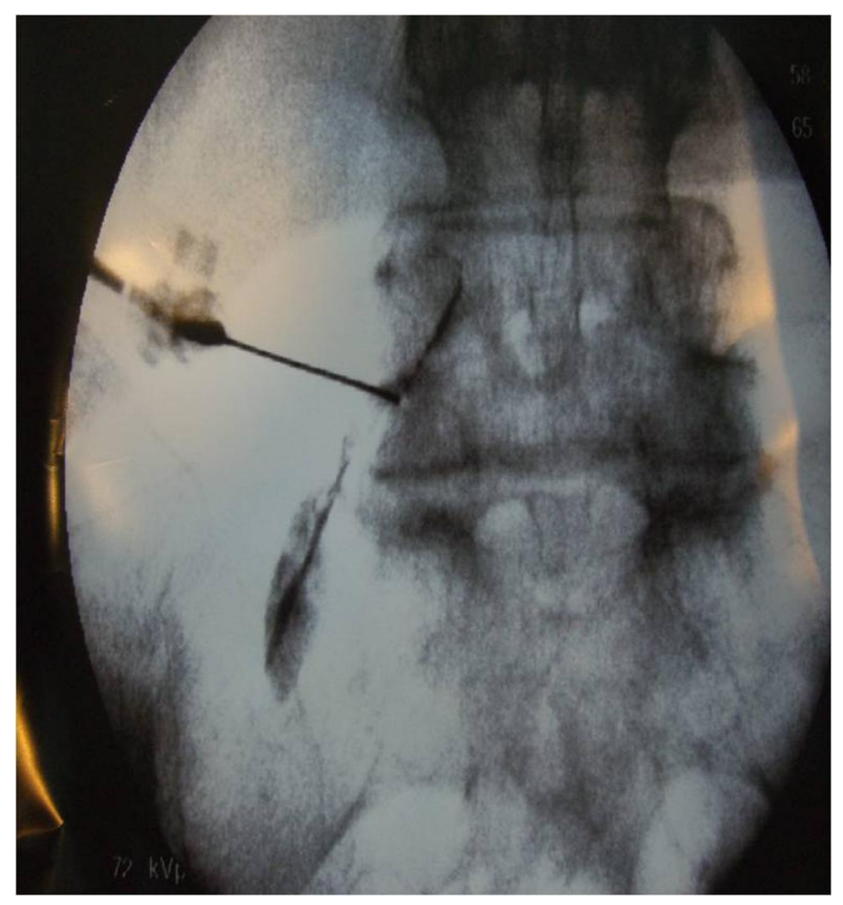

Figure 3 A fluoroscopy image of the lumbosacral spine in the A-P view demonstrating an extra-foraminal percutaneous approach to the L4 nerve root. The tip of the spinal needle is passing through the foramen of the exiting L4 nerve root. A contrast material is injected to delineate the nerve root and the nearby epidural space before the intended injection of medications.

The diagnosis of sciatica was made clinically by a neurosurgeon and confirmed by a finding of lumbar disc prolapse (LDP) or foraminal stenosis (FS) on MRI. The pain was assessed using the visual analogue scale (VAS) score during the first visit to the outpatient clinic, in the operating room before and after the procedure/injection, and during their follow-up visits to the outpatient clinic.

Information on which root was targeted, pain score in the clinic and pain score before and after the procedure, and any procedural complications were obtained from the patients' outpatient clinic notes, the MRI findings, and the procedural notes. Follow-up notes over three months documented the patients' course of pain and need for surgery.

\section{Statistical Analysis}

All data analysis was performed using SAS 9.4 software. Age was categorized into 6 categories; ages 20-29, 30-39, $40-49,50-59,60-69$, and $\geq 70$. Improvement in symptoms was used as a dichotomous variable using a VAS score of $3 / 10$ as a cutoff point, where values of $3 / 10$ or less were considered an improvement of symptoms. The distribution of different factors was assessed in the whole study population. Those factors included age, gender, presenting symptoms, recurrence of symptoms, diagnosis for the cause of pain, and symptom improvement. The study population was categorized by the recurrence of symptoms, and a Chi-square test was used to test if there are differences in the distribution of age, gender, presenting symptoms, diagnosis for the cause of pain (Facet, Lumbar disc herniation, SIJ arthritis), the level of pathology and the improvement of symptoms between the two categories.

\section{Results}

In the remaining 76 patients, the age distribution of the whole study population was as follows: $7(9.21 \%)$ in the ages of 20-29 years, $10(13.16 \%)$ ages 30-39, $16(21.05 \%)$ ages 40-49, 23 (30.26\%) ages 50-59, 12 (15.79\%) ages 60-69, and $8(10.53 \%)$ above 70 years old. In the whole study population, $51(67.11 \%)$ were females, and $25(32.89 \%)$ were males. 33 (43.42\%) patients presented with low back pain, $1(1.32 \%)$ presented with Sciatica, and $42(55.26 \%)$ presented with both low back pain and Sciatica.

The distribution of the diagnoses for the cause of the pain was as follows: $10(13.16 \%)$ with Facet joint Osteoarthritis, 54 patients $(71.05 \%)$ diagnosed with Lumbar disc herniation, $11(14.47 \%)$ with SIJ Osteoarthritis, and 1 (1.32\%) with Lumbar disc herniation and SIJ Osteoarthritis.

Out of the 10 patients diagnosed with Facet joint Osteoarthritis, 1 was at the L4-L5 level, 5 at the L5-S1 level, and 4 had multiple levels. Out of the 54 patients diagnosed with Lumbar disc herniation, 2 were at the L2- 
L3 level, 2 at the L3-L4 level, 32 at the L4-L5 level, 13 at the L5-S1 level, and 5 had multiple levels. Out of the 76 patients, 72 (94.74\%) had improved symptoms, while $4(5.26 \%)$ did not show any improvement. [Table 1]

Out of the 76 patients, $45(60.53 \%)$ had pain recurrence, while $30(39.47 \%)$ did not. Using the Chi-square test, there were no significant differences between the 2 recurrence groups concerning age $(\mathrm{P}=0.09)$, gender $(\mathrm{P}=1.00)$, presenting symptoms $(\mathrm{P}=0.09)$, diagnosis for cause of pain $(\mathrm{P}=0.45)$, pathology level $(\mathrm{P}=0.49)$, and improvement of symptoms $(\mathrm{P}=0.65)$ [Table 2].

When assessing improvement of symptoms after the procedure, 69 patients $(90.7 \%)$ improved immediately after the procedure, while the other 7 patients $(9.3 \%)$ did not experience any improvement and eventually were treated surgically by microscopic interlinear fenestration and sequestrectomy. Out of those 69 patients who improved, 22 patients $(28.9 \%$ of the total) showed longterm relief of symptoms after the injection and did not experience any relapse during the following 3 months.

The remaining 46 patients $(60.53 \%$ of the total) experienced recurrence of symptoms of different severities over the following three months. Those were managed differently according to their preferences and the severity of the pain; they were also offered a second trial of conservative therapy or surgery. 19 of 46 patients improved satisfactorily with further conservative treatment, and the other 28 patients eventually received surgery, making the total number of patients who received surgery 35 patients. The total number of patients who did not need surgery was 41 patients (53.9\%). 19 patients (25\%) showed recurrence of pain after the SNRB and improved with further conservative therapy. The remaining 22 patients $(28.9 \%)$ had persistent improvement after the SNRB. Those patients were further followed up, and all had satisfactory or permanent relief of their radicular pain after 6 months.

\section{Discussion}

Most patients with Lumbar radiculopathy usually improve on conservative treatment, considering that there are no red flags for urgent surgery. ${ }^{12}$ In intractable cases in which pain is persistent and fails to respond to any treatment, surgery is advised. ${ }^{5,8}$ One of the most common types of surgery is microdiscectomy, which is the surgical removal of part of the disc, performed with the use of an operating microscope or other magnifying tools. ${ }^{13}$ Other minimally invasive surgical techniques, such as endoscopic surgery, have recently been developed and are being a standard practice in many
Table I Distribution of Different Factors in the Study Population

\begin{tabular}{|c|c|}
\hline Factor & $\mathbf{N}(\%)$ \\
\hline \multicolumn{2}{|l|}{ Age } \\
\hline $20-29$ & $7(9.21)$ \\
\hline $30-39$ & $10(13.16)$ \\
\hline $40-49$ & $16(21.05)$ \\
\hline $50-59$ & $23(30.26)$ \\
\hline $60-69$ & 12 (I5.79) \\
\hline$\geq 70$ & $8(10.53)$ \\
\hline \multicolumn{2}{|l|}{ Gender } \\
\hline Female & $5 I(67.1 I)$ \\
\hline Male & $25(32.89)$ \\
\hline \multicolumn{2}{|l|}{ Presenting symptom } \\
\hline Low back pain & $33(43.42)$ \\
\hline Sciatica & I (I.32) \\
\hline Low back pain and Sciatica & $42(55.26)$ \\
\hline \multicolumn{2}{|l|}{ Diagnosis for cause of pain } \\
\hline Facet joint Osteoarthritis & $10(13.16)$ \\
\hline Lumbar disc herniation & $54(7 \mid .05)$ \\
\hline SIJ Osteoarthritis & II (I4.47) \\
\hline Lumbar disc herniation and SIJ Osteoarthritis & I (I.32) \\
\hline \multicolumn{2}{|l|}{ Pathology level } \\
\hline \multicolumn{2}{|l|}{ Facet joint Osteoarthritis } \\
\hline L4-L5 only & I (I.32) \\
\hline L5-SI only & $5(6.58)$ \\
\hline Multiple levels & $4(5.26)$ \\
\hline \multicolumn{2}{|l|}{ Lumbar disc herniation } \\
\hline L2-L3 only & $2(2.63)$ \\
\hline L3-L4 only & $2(2.63)$ \\
\hline L4-L5 only & $32(42.11)$ \\
\hline L5-SI only & $13(17.11)$ \\
\hline Multiple levels & $5(6.58)$ \\
\hline SIJ Osteoarthritis & II (I4.47) \\
\hline Lumbar disc herniation and SIJ Osteoarthritis & I (I.32) \\
\hline \multicolumn{2}{|l|}{ Improvement of symptoms } \\
\hline No & $4(5.26)$ \\
\hline Yes $^{\mathrm{a}}$ & $72(94.74)$ \\
\hline \multicolumn{2}{|l|}{ Recurrence } \\
\hline No & $30(39.47)$ \\
\hline Yes & $46(60.53)$ \\
\hline
\end{tabular}

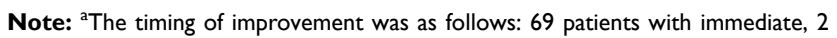
after 2 weeks, and I after 3 months.

Abbreviations: $\mathrm{N}$, number; \%, percentage; SIJ, sacroiliac joint.

centers. ${ }^{14,15}$ Although there is evidence that early surgery in patients with sciatica provides for better short-term relief of back pain as compared to prolonged conservative care, the evidence is low quality, and no significant differences were found between surgery and usual conservative care in any of the clinical outcomes after 1 and 2 years. ${ }^{4}$ 
Table 2 Distribution of Factors by Recurrence

\begin{tabular}{|c|c|c|c|}
\hline & $\begin{array}{l}\text { No } \\
\text { Recurrence of } \\
\text { Symptoms } \\
(n=30)\end{array}$ & $\begin{array}{l}\text { Recurrence } \\
\text { of } \\
\text { Symptoms } \\
(n=46)\end{array}$ & $\begin{array}{l}\text { Chi } \\
\text { Square } \\
\text { P value }\end{array}$ \\
\hline & N (\%) & N (\%) & \\
\hline $\begin{array}{l}\text { Age } \\
20-29 \\
30-39 \\
40-49 \\
50-59 \\
60-69 \\
\geq 70\end{array}$ & $\begin{array}{l}3(10.00) \\
7(23.33) \\
6(20.00) \\
4(13.33) \\
6(20.00) \\
4(13.33)\end{array}$ & $\begin{array}{l}4(8.70) \\
3(6.52) \\
10(21.74) \\
19(41.30) \\
6(13.04) \\
4(8.70)\end{array}$ & 0.09 \\
\hline $\begin{array}{l}\text { Gender } \\
\text { Female } \\
\text { Male }\end{array}$ & $\begin{array}{l}20(66.67) \\
10(33.33)\end{array}$ & $\begin{array}{l}31 \text { (67.39) } \\
15(32.61)\end{array}$ & 1.00 \\
\hline $\begin{array}{l}\text { Presenting symptom } \\
\text { Low back pain } \\
\text { Sciatica } \\
\text { Low back pain and Sciatica }\end{array}$ & $\begin{array}{l}9(30.00) \\
1(3.33) \\
20(66.67)\end{array}$ & $\begin{array}{l}24(52.17) \\
0(0.00) \\
22(47.83)\end{array}$ & 0.09 \\
\hline $\begin{array}{l}\text { Diagnosis for cause of pain } \\
\text { Facet joint Osteoarthritis } \\
\text { Lumbar disc herniation } \\
\text { SIJ Osteoarthritis } \\
\text { Lumbar disc herniation } \\
\text { and SIJ Osteoarthritis }\end{array}$ & $\begin{array}{l}I(3.33) \\
24(80.00) \\
5(16.67) \\
0(0.00)\end{array}$ & $\begin{array}{l}9(19.57) \\
30(65.22) \\
6(13.04) \\
1(2.17)\end{array}$ & 0.45 \\
\hline $\begin{array}{l}\text { Pathology level } \\
\text { Facet joint Osteoarthritis } \\
\text { L4-L5 Only } \\
\text { L5-SI Only } \\
\text { Multiple levels } \\
\text { Lumbar disc herniation } \\
\text { L2-L3 Only } \\
\text { L3-L4 Only } \\
\text { L4-L5 Only } \\
\text { L5-SI Only } \\
\text { Multiple levels } \\
\text { SIJ Osteoarthritis } \\
\text { Lumbar disc herniation } \\
\text { and SIJ Osteoarthritis }\end{array}$ & $\begin{array}{l}0(0.00) \\
0(0.00) \\
\text { I }(3.33) \\
\text { I }(3.33) \\
\text { I }(3.33) \\
13(43.33) \\
7(23.33) \\
2(6.67) \\
5(16.67) \\
0(0.00)\end{array}$ & $\begin{array}{l}\text { I }(2.17) \\
4(8.70) \\
4(8.70) \\
1(2.17) \\
0(0.00) \\
19(41.30) \\
6(13.04) \\
4(8.70) \\
6(13.04) \\
1(2.17)\end{array}$ & 0.49 \\
\hline $\begin{array}{l}\text { Improvement of symptoms } \\
\text { No } \\
\text { Yes }\end{array}$ & $\begin{array}{l}2(6.67) \\
28(93.33)^{\mathrm{a}}\end{array}$ & $\begin{array}{l}2(4.35) \\
44(95.65)^{b}\end{array}$ & 0.65 \\
\hline
\end{tabular}

Notes: ${ }^{a} 2$ patients after 2 weeks, I after 3 months, and 25 immediately after procedure. ${ }^{\mathrm{b}} 44$ patients immediately after procedure

Abbreviations: $\mathrm{N}$, number; \%, percentage; SIJ, sacroiliac joint.

Back surgery with little success is associated with significant healthcare costs and risks to patients. ${ }^{16}$ Many patients hesitate to undergo surgery or have a high risk for general anesthesia. The long waiting list for surgery remains an obstacle in many countries and centers, and it may take weeks or even months. ${ }^{17,18}$ For non-insured patients, the cost of surgery is another issue. In our institution, the average waiting time for a microdiscectomy is 2-3 months, and the average cost for non-insured patients is 3000 U.S. Dollars. Searching for a fast and reasonable alternative for such patients is necessary.

As a quick intervention that does not necessitate general anesthesia, SNRB can be used as a therapeutic procedure and a diagnostic procedure useful for selecting pain-mediating nerve roots. ${ }^{10}$ Its effect as a therapeutic procedure is unpredictable, mostly short-acting in most patients, and recurrences are expected. ${ }^{16}$ Still, it can create a time window for pain relief. ${ }^{2}$ Although long-lasting improvement is possible, the long-term effects of the medications cannot be predicted. ${ }^{16,18}$ Usually, the immediate effect is from the local anesthetic injected; this wears off in a few hours. The steroid starts working in about 2-3 days, and its effect can last for several days to a few months. ${ }^{10}$ However, it remains a good, fast, and less expensive alternative to surgery.

During our literature review, we were unable to find a direct comparison between surgical microdiscectomy and SNRB. One relatively related trial was the NERVES (NErve Root block VErsus Surgery) trial, which aimed to compare the cost and clinical effect of surgical microdiscectomy versus transforaminal epidural steroid injection (TFESI) to treat prolapsed intervertebral disc inducing sciatica. ${ }^{17}$

In our study, $69(90.7 \%)$ of the 76 patients improved immediately after the procedure, where VAS dropped from 10 to 3 directly. Similar results were also seen in a study conducted in December 2009 in which the VAS dropped immediately from 7.8 to 2.9 after one SNRB. In the same study, a better treatment effect was observed for FS patients after a one-month and three-month period. ${ }^{19}$

When assessing the recurrence of symptoms by type of pathology, $90 \%$ of patients with facet joint osteoarthritis had a recurrence of symptoms, and $55.6 \%$ of patients with lumbar disc herniation had recurrence of symptoms. Our results are similar to the results of Kanayama et al, where they found that the recurrence of pain was more common in patients with mechanical compression than in those with disc herniation alone. ${ }^{20}$

Out of the total number of our sample (76), 22 patients (28.9\%) showed long-term relief of symptoms after one SNRB and did not experience any recurrence of symptoms after six months. This was also seen in a study that showed 
relief of symptoms in $20 \%$ of patients throughout the follow-up period of six months. ${ }^{2}$

This made our primary focus on the clinical benefits of SNRB in treating patients with lumbosacral radiculopathy caused by LDP or FS to find out the percentage of longterm pain relief; therefore, SNRB can delay and sometimes cease the need for surgery.

\section{Limitations}

The high exclusion criteria limited our sample size to 76 . The sample included patients who have lumbosacral radiculopathy caused by lumbar disc herniation due to both LDP and FS.

In our analysis, we included both pathologies as a single sample. Further studies should be conducted to find out the relation between the underlying pathology and the response to SNRB.

Furthermore, it is recommended that longer follow-up periods should be taken into consideration.

\section{Conclusion}

Therapeutic selective nerve root block is an essential procedure in the pain management of patients with lumbosacral radiculopathy caused by lumbar disc prolapse and foraminal stenosis. Our study showed that avoidance of surgery could be achieved in up to $54 \%$ of patients, and long-term pain relief can be achieved in up to $29 \%$ of patients after a single SNRB. This makes SNRB a very good second line of management and a very valuable procedure to avoid surgery and achieve a long-term satisfactory relief of pain and possibly permanent relief of pain. It remains a fast intervention that can be performed on a day case basis, necessitating no anesthesia, with negligible side effects and lower cost.

\section{Disclosure}

The authors report no financial or non-financial conflicts of interest in this work.

\section{References}

1. Alexander CEVM. Lumbosacral Radiculopathy. 2020.

2. Arun-Kumar K, Jayaprasad S, Senthil K, Lohith H, Jayaprakash KV. The outcomes of selective nerve root block for disc induced lumbar radiculopathy. Malaysian Orthopaedic j. 2015;9(3):17-22. doi:10. 5704/MOJ.1511.002

3. Hoy D, Brooks P, Blyth F, Buchbinder R. The epidemiology of low back pain. Best Pract Res Clin Rheumatol. 2010;24(6):769-781. doi:10.1016/j.berh.2010.10.002
4. Jacobs WC, van Tulder M, Arts M, et al. Surgery versus conservative management of sciatica due to a lumbar herniated disc: a systematic review. Eur Spine j. 2011;20(4):513-522. doi:10.1007/s00586-0101603-7

5. Wenger HC, Cifu AS. Treatment of low back pain. JAMA. 2017;318 (8):743-744. doi:10.1001/jama.2017.9386

6. Zaina F, Tomkins-Lane C, Carragee E, Negrini S. Surgical versus non-surgical treatment for lumbar spinal stenosis. Cochrane Database Syst Rev. 2016;2016(1):CD010264-CD010264.

7. Koes BW, van Tulder MW, Peul WC. Diagnosis and treatment of sciatica. BMJ (Clinical Research Ed). 2007;334(7607):1313-1317. doi:10.1136/bmj.39223.428495.BE

8. Chou R, Loeser JD, Owens DK, et al. Interventional therapies, surgery, and interdisciplinary rehabilitation for low back pain: an evidence-based clinical practice guideline from the American Pain Society. Spine. 2009;34(10):1066-1077. doi:10.1097/BRS.0b013e 3181a1390d

9. Pfirrmann CW, Oberholzer PA, Zanetti M, et al. Selective nerve root blocks for the treatment of sciatica: evaluation of injection site and effectiveness - a study with patients and cadavers. Radiology. 2001;221(3):704-711. doi:10.1148/radiol.2213001635

10. Anderberg L, Annertz M, Persson L, Brandt L, Säveland H. Transforaminal steroid injections for the treatment of cervical radiculopathy: a prospective and randomised study. Eur Spine j. 2007;16 (3):321-328. doi:10.1007/s00586-006-0142-8

11. Kikuchi S. Anatomical and experimental studies of nerve root infiltration. Nihon Seikeigeka Gakkai Zasshi. 1982;56(7):605-614.

12. Negrini S, Giovannoni S, Minozzi S, et al. Diagnostic therapeutic flow-charts for low back pain patients: the Italian clinical guidelines. Eura Medicophys. 2006;42(2):151-170.

13. Sobottke R, Röllinghoff $M$, Siewe J, et al. Clinical outcomes and quality of life 1 year after open microsurgical decompression or implantation of an interspinous stand-alone spacer. Minimally Invasive Neurosurg. 2010;53(4):179-183.

14. Clark AJ, Safaee MM, Khan NR, Brown MT, Foley KT. Tubular microdiscectomy: techniques, complication avoidance, and review of the literature. Neurosurg Focus. 2017;43(2):E7. doi:10.3171/2017.5. FOCUS17202

15. Skovrlj B, Gilligan J, Cutler HS, Qureshi SA. Minimally invasive procedures on the lumbar spine. World j Clin Cases. 2015;3(1):1-9. doi:10.12998/wjcc.v3.i1.1

16. Beynon R, Elwenspoek MMC, Sheppard A, et al. The utility of diagnostic selective nerve root blocks in the management of patients with lumbar radiculopathy: a systematic review. BMJ Open. 2019;9 (4):e025790. doi:10.1136/bmjopen-2018-025790

17. Wilby MJ, Hopkins C, Bedson E, et al. Nerve root block versus surgery (NERVES) for the treatment of radicular pain secondary to a prolapsed intervertebral disc herniation: study protocol for a multi-centre randomised controlled trial. Trials. 2018;19(1):475. doi:10.1186/s13063-018-2677-5

18. Price C, Arden N, Coglan L, Rogers P. Cost-effectiveness and safety of epidural steroids in the management of sciatica. Health Technol Assessment. 2005;9(33):1-58, iii.

19. Kim S-B, Jeon T-S, Park W-K, Jo S-K, Kim Y-S, Hwang C-M. Transforaminal selective nerve root blocks for treating single lumbosacral radiculopathy: the short-term outcome and efficiency. $J$ Korean Orthopaedic Assoc. 2009;44.

20. Kanayama M, Oha F, Hashimoto T. What types of degenerative lumbar pathologies respond to nerve root injection? A retrospective review of six hundred and forty one cases. Int Orthop. 2015;39 (7):1379-1382. doi:10.1007/s00264-015-2761-3 


\section{Publish your work in this journal}

The Journal of Pain Research is an international, peer reviewed, open access, online journal that welcomes laboratory and clinical findings in the fields of pain research and the prevention and management of pain. Original research, reviews, symposium reports, hypothesis formation and commentaries are all considered for publication. The manuscript management system is completely online and includes a very quick and fair peer-review system, which is all easy to use. Visit http:// www.dovepress.com/testimonials.php to read real quotes from published authors. 